\title{
Study On Inventory Model Considering Fairness Concerns Under Permissible Delay In Payments
}

\author{
Wang Dao-ping, Zhang Bo-qing \\ Donlinks School of Economics and Management, University of Science and Technology Beijing, Beijing, 100083
}

Keywords: fairness concerns; Stackelberg games; the delay of payment

\begin{abstract}
Optimal retailer's pricing and replenishment policies and supplier's delay-in-payments policy considering fairness concerns under permissible delay in payments is studied in this paper. A model of Stackelberg game between the fairness neutral supplier and the fairness concerned retailer is developed. A numerical example is given to verify the validity of the proposed model and conduct sensitivity analysis on parameters. The results show that, with the increase of the retailer's fairness concerns, the retailer should lower the price, increase the order quantity, and the supplier's optimal delay-in-payments should be shortened; when the fairness concerns coefficient satisfies certain conditions, the utility of the retailer and supplier is higher than without fairness concerns.
\end{abstract}

\section{Introduction}

As an important means of promotion, deferred payment is widely used in economic activities. In general merchandise trade, the buyer will pay for the goods immediately after they receive it when they don t have capital constraint. While some enterprises that don t have enough cash flow have strong willing to be provided a deferred payment period by sellers during which the buyer can earn some money to afford the debt. On the other hand, sellers often take measures such as deferred payment strategy to stimulate order quantity. Therefore, deferred payment has been widely recognized used. But it should be noted that this promotion strategy also bring credit risk to sellers which is more likely to incur fairness concern of sellers. In real life, enterprises do not always behave to maximize their profit. Sometimes, people express strongly concern of fairness to their cooperators. When enterprises pay attention to fairness, channel members in supply chain are easy to achieve a winwin situation and the interests of the members can be longterm guarantee. The fairness concern will lead members to behave to maximize their utility rather than profit. So, Therefore, it is of great theoretical value and practical significance to study the influence of the fair concern on the optimal strategy of the decision maker under the condition of delay payment.

At present, many domestic and foreign scholars have studied the inventory model considering deferred payment. Goyal introduced delay payment mechanism into economic order quantity model firstly and then a lot of scholars have made a lot of extensions to the model ${ }^{[1]}$.Hwang proposed the method of determining the optimal extension payment term in the case of the supplier's point of view, considering the price and order quantity of the product are retailer's decision variable ${ }^{[2]}$. Huang studied the minimum inventory quantity and optimal order quantity of deteriorating products under the condition of fuzzy demand ${ }^{[3]}$. Based on delay payment, Liang-Yuh and Kai-Wayne take quantity discount contract and allowance of inventory shortage into account and solve the optimal order quantity and shortage period ${ }^{[4]}$. Ghosh established EOQ model of perishable products considering delay payment ${ }^{[5]}$. Differing from literature [4] and [5], literature [6] proposed an inventory model which include 3 situations divided according to relationship among shortage period, order period and period of delay payments. Aiming at a supply chain include one manufacturer and multiple distributors Yang shu established a Stackelberg game model to make optimal delay payment decision for manufacture and optimal order quantity decisions for distributors ${ }^{[7]}$.

Literatures above assume that enterprises in supply chain make decisions to maximize their profit. But in reality, many enterprise pay attention to fairness. Cui introduced fairness concern to research of channel coordination first and found that wholesale price contract can coordinate supply chain when members all concern fairness and demand function is linear ${ }^{[8]}$. Considering a two-stage supply chain, Du studied the influence of retailer's fairness concern on effectiveness of wholesale price contract, revenue sharing contract and buy back contract respectively ${ }^{[9]}$. Liu studied the influence of retailer's fairness concern and manufacture's fairness concern on price and inventory decision respectively ${ }^{[10]}$. Under the research background of VMI, Zhao and Lv Reveals the boundary conditions of whether fairness concern influence performance of overall supply chain or not ${ }^{[11]}$.

In conclude, many scholars have introduced the theory of fairness concern to the channels cooperation, supply chain coordination, supplier inventory management, and has achieved fruitful research results. But seldom literature consider the strategy of delay payment. So this paper introduces fairness concern and delay payment into EOQ model simultaneously. Thus, establishes a kind of Stackelberg game based on a two-stage supply chain to solve supplier's optimal decision of delay payment and retailer's optimal price and order decision. 


\section{Symbolic \\ Description \\ And Model Hypothesis}

Under the research background of a two-stage supply chain that contains a fairness neutral supplier and a fairness concern retailer, the strategy of delay payment is implemented by supplier to stimulate retailer's order quantity. And supplier loss interest during the delay period. In the course of the game, supplier the dominant role and decide the delay period while retailer make decision on price and order quantity to maximize it's utility which can be calculated by equation(1).

$U\left(\pi_{r}\right)=\pi_{r}+\lambda\left(\pi_{s}-k \pi_{r}\right)$

Among equation(1), $\pi_{r}$ and $\pi_{s}$ represent retailer and supplier's profit respectively. $\lambda$ means fairness concern ratio and satisfy the inequation $0<\lambda<1 . k$ is positive real number and means relative contribution rate. $\lambda$ and $k$ satisfy the inequation $(1-\lambda k)>0$. Other symbols and corresponding definitions used in the model are as follows:

$D$ : demand rate. That is product demand for retailers in unit time

$A$ : fixed cost got order,

$c$ : order cost per unit,

$c_{0}$ : cost of production per unit,

$h$ : $h c$ is retailer's inventory holding cost per unit for unit time,

$p$ : retail price,

$T$ : retailer's ordering cycle,

$B$ : shortage quantity at the end of ordering cycle,

$r$ : retailer's back order cost per unit for unit time,

$s$ : order loss cost per unit,

$\eta$ : delay satisfaction rate of shortage quantity,

$Q$ : retailer's order quantity,

$M$ : deferred payment period given by supplier to retailer,

$I_{e}$ : annual interest rate of income,

$I_{k}$ : annual interest rate of payment,

$I(t)$ : retailer's inventory stock at time $t$, where $0 \leq t \leq T$.

Hypothesis of this paper are as follows:

(1) the delivery of the goods is instantaneous.

(2)Before the deadline of deferred payment, retailer saves it's revenue to bank for interest with rate revenue rate $I_{e}$. After deferred payment period, retailer need to pay interest for inventory hold cost with payment rate $I_{k}$.

(3) the retailer has to pay the loan in $t=\mathrm{M}$.

\section{Model building}

The demand rate that retailer faces is $D=a-b p$. $a$ represent potential demand rate in the market. $b$ is demand price elasticity. So, retailer's inventory satisfy equation $I(t)=\left(F T^{-}\right.$ $t) D, \quad 0 \leq t \leq F T$.

$F T$ satisfy equation $I(F T)=0$. If products are all sold before the next replenishment, situation of shortage is happened, and a part of consumer accept to wait for replenishment. The proportion of consumer in those who face shortage is $\eta$. Figure 1 gives a brief exhibition of inventory quantity at every time. So order quantity of every cycle $Q$ is $[D F T+\eta D(1-F) T]$

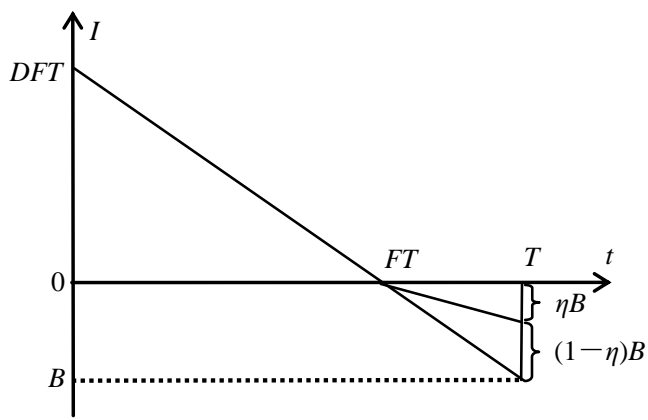

Figure 1: Inventory quantity at every time

\subsection{Supplier's profit per time}

Supplier's income is revenue come from products wholesaled to retailer. It's cost is lost of revenue interest caused by delay payment strategy. Supplier's profit per time can be calculated by equation (2).

$$
\pi_{s}=\left(c-c_{0}-c I_{e} M\right)(F+\eta(1-F)) D
$$

\subsection{Retailer's utility per time}

According to equation (1), we need to calculate retailer's and supplier's profit to obtain retailer's utility. Thus we need to analyze retailer's cost. The component of it's cost include order cost $A / T$, wholesale cost $c Q / T$, Inventory holding cost $h c D F^{2} T / 2$, shortage cost $S C$ and interest cost $I C$ which equals interest payment for inventory holding cost subtract interest revenue for sale income. Shortage cost $S C$ consists defer delivery cost and order lost cost. $S C$ can be calculated by equation (3).

$$
\begin{aligned}
S C & =\frac{1}{T}\left(\frac{r \eta D(1-F)^{2} T^{2}}{2}+s D T(1-\eta)(1-F)\right) \\
& =\frac{r \eta D T(1-F)^{2}}{2}+s D(1-\eta)(1-F)
\end{aligned}
$$

When it comes to $I C$, we need to discussion on two cases. One case is the situation when deferred payment period satisfy inequation $M \leq F T$, while the other case is the situation when $M$ satisfy inequation $M>F T$. $I C$ can be calculated by equation (4).

$$
I C= \begin{cases}-\frac{p I(t)}{T} \int_{0}^{M} D t d t+\frac{c I_{k}}{T} \int_{M}^{F T} I(t) d t & , M \leq F T \\ -\frac{p I_{e}}{T}\left(\int_{0}^{F T} D t d t+D F T(M-F T)\right) & , M<F T\end{cases}
$$

So, retailer's profit per time $\pi_{r}$ is

$$
\begin{aligned}
\pi_{r}= & (p-c) D-\frac{A}{T}-\frac{h c D F^{2} T}{2}-\frac{r \eta D(1-F)^{2} T}{2} \\
& -(s+p-c)(1-\eta)(1-F) D+I C
\end{aligned}
$$

Then, we substitution $\pi_{r}$ and $\pi_{s}$ in equation (1) through equation (3) and (5) to obtain retailer's utility per time $U\left(\pi_{r}\right)$. 


\subsection{Stackelberg game model}

According to retailer's and supplier's decision objectives, the Stackelberg game model can be describe as following: $\max \pi_{s}=\left(c-c_{0}-c I_{e} M\right)(F+\eta(1-F))(a-b p)$ s.t. $\{p, T\}=\arg \max U\left(\pi_{r}\right)$

\section{Model Solution}

\subsection{Retailer's decision}

Retailer's decisions which include price $p$ and ordering cycle $T$ on two cases consisting of situation when $M \leq F T$ and $M>F T$ hold respectively.

(1) $M \leq F T$

According to equation (1), (2) and (5), first-order partial derivatives $\partial U\left(\pi_{r}\right) / \partial p$ and $\partial \Delta U\left(\pi_{r}\right) / \partial T$ are as following:

$$
\begin{aligned}
& \frac{\partial U\left(\pi_{r}\right)}{\partial p}=(1-k \lambda)\left(\gamma_{11}(D-b p)+\gamma_{12}\right)+\lambda \gamma_{13} \\
& \frac{\partial U\left(\pi_{r}\right)}{\partial T}=(1-k \lambda)\left(\begin{array}{l}
\frac{A}{T^{2}}-\frac{h c D F^{2}+r \eta D(1-F)^{2}}{2} \\
-\frac{p I_{e} D M^{2}+c I_{k} D\left(F^{2} T^{2}-M^{2}\right)}{2 T^{2}}
\end{array}\right)
\end{aligned}
$$

$\gamma_{11}, \gamma_{12}$ and $\gamma_{13}$ are as following:

$$
\begin{aligned}
& \gamma_{11}=1-(1-\eta)(1-F)+\frac{I_{e} M^{2}}{2 T} \\
& \gamma_{12}=b\left(\begin{array}{l}
c+(s-c)(1-\eta)(1-F) \\
+\frac{h c F^{2} T^{2}+r \eta(1-F)^{2} T^{2}+c I_{k}(F T-M)^{2}}{2 T}
\end{array}\right) \\
& \gamma_{13}=-b\left(c-c_{0}-c I_{e} M\right)(F+\eta(1-F))
\end{aligned}
$$

Let $\partial U\left(\pi_{r}\right) / \partial p$ and $\partial \Delta U\left(\pi_{r}\right) / \partial T$ equal 0 , and we can obtain optimal price $p_{1}{ }^{*}$ and ordering cycle $T_{1}{ }^{*}$ when $M \leq F T$ holds:

$$
\begin{aligned}
& p_{1}^{*}=\frac{(1-k \lambda)\left(a \gamma_{11}+\gamma_{12}\right)+\lambda \gamma_{13}}{2 b \gamma_{11}(1+k \lambda)} \\
& T_{1}^{*}=\sqrt{\frac{2 A+\left(c I_{k}-p I_{e}\right)\left(a-b p_{1}^{*}\right) M^{2}}{\left(h c F^{2}+r \eta(1-F)^{2}+c I_{k} F^{2}\right)\left(a-b p_{1}^{*}\right)}}
\end{aligned}
$$

If $F T_{1}{ }^{*}<M$ or equation (8) and (9) are unsolvable, the optimal ordering cycle is $M / F$. Substitute $T$ with $M / F$ in equation (8) and the optimal price is get.

(2) $M>F T$

Similar to situation when $M \leq F T$ is satisfied, optimal price $p_{2}{ }^{*}$ and ordering cycle $T_{2}{ }^{*}$ when $M>F T$ holds are as following:

$$
\begin{aligned}
& p_{2}{ }^{*}=\frac{(1-k \lambda)\left(a \gamma_{21}+\gamma_{22}\right)+\lambda \gamma_{23}}{2 b \gamma_{21}(1+k \lambda)} \\
& T_{2}{ }^{*}(p)=\sqrt{\frac{2 A}{\left(\left(h c+p I_{e}\right) F^{2}+r \eta(1-F)^{2}\right)(a-b p)}}
\end{aligned}
$$

$\gamma_{11}, \gamma_{12}$ and $\gamma_{13}$ are as following:

$$
\gamma_{21}=1-(1-\eta)(1-F)+F I_{e}\left(M-\frac{1}{2} F T\right)
$$

$$
\begin{aligned}
& \gamma_{22}=b\left(c+(s-c)(1-\eta)(1-F)+\frac{h c F^{2} T+r \eta(1-F)^{2} T}{2}\right) \\
& \gamma_{23}=-b\left(c-c_{0}-c I_{e} M\right)(F+\eta(1-F))
\end{aligned}
$$

If $F T_{1}{ }^{*} \geq M$ or equation (10) and (11) are unsolvable, the optimal ordering cycle is $M / F$. Substitute $T$ with $M / F$ in equation (9) and the optimal price is get.

\subsection{Supplier's decision}

Supplier's profit per time can be get by substituting $p$ in equation (2) with $p_{1}{ }^{*}$ and $p_{2}{ }^{*}$ :

$$
\begin{aligned}
\pi_{s}= & \left(c-c_{0}-c I_{e} M\right) \times(F+\eta(1-F)) \\
& \times\left(\frac{(1-k \lambda)\left(a \gamma_{i 1}-\gamma_{i 2}\right)+\lambda \gamma_{i 3}}{2 \gamma_{i 1}(1-k \lambda)}\right)
\end{aligned}
$$

$i=1$ and $i=2$ represent the situations when $M \leq F T$ and $M>$ $F T$ holds respectively. Supplier make decision on delay payment period $M$, we construct it's Lagrange function as equation (13), considering $M$ has constrain $M \leq F T$ or $M>$ FT.

$\max L\left(M, \mu_{i 1}, \mu_{i 2}\right)=\left(c-c_{0}-c I_{e} M\right) \times(F+\eta(1-F))$

$$
\times\left(\frac{(1-k \lambda)\left(a \gamma_{i 1}-\gamma_{i 2}\right)+\lambda \gamma_{i 3}}{2 \gamma_{i 1}(1-k \lambda)}\right)+\mu_{i 1} g_{i 1}(M)+\mu_{i 2} g_{i 2}(M)
$$

In equation (13), $g_{i 1}, g_{i 2}, \mu_{i 1}$ and $\mu_{i 2}$ satisfy equation or inequation as following:

$$
\begin{aligned}
& g_{11}=M \\
& g_{12}=F T-M \\
& g_{21}=M-F T \\
& g_{22}=T-M \\
& \mu_{i 1} \geq 0 \\
& \mu_{i 2} \geq 0
\end{aligned}
$$

Then, Karush-Kuhn-Tucker conditions for Lagrange function (13) are as following:

$$
\left\{\begin{array}{l}
\frac{\partial L\left(M, \mu_{i 1}, \mu_{i 2}\right)}{\partial M}=0 \\
\mu_{i 1} g_{i 1}(M)=0 \\
\mu_{i 2} g_{i 2}(M)=0 \\
\mu_{i 1}, \mu_{i 2} \geq 0 \\
i=1,2
\end{array}\right.
$$

Optimal delay payment period $M^{*}$ can be obtained by solving equation set (14). Substitute $M$ with $M^{*}$ in equation (8), (9), (10) ,(11) and we can get retailer's optimal decisions. Analytic solutions for equation set (14) are hard to achieve, so we solve equation set (14) by software matlab in numerical example and make sensitive analysis based on it. 


\section{Numerical Example}

A numerical example is given to analyze the effect of $\lambda$ and $k$ on optimal decisions. Values of main parameters in the model are given in table 1 .

\begin{tabular}{|c|c||c|c|}
\hline parameter & value & parameter & value \\
\hline$a$ & 100000 & $r$ & 100 \\
$b$ & 40 & $s$ & 200 \\
$A$ & 20000 & $\eta$ & $40 \%$ \\
$c_{0}$ & 1600 & $I_{e}$ & 0.05 \\
$c$ & 2000 & $I_{k}$ & 0.10 \\
$h$ & $20 \%$ & $\lambda$ & 0.25 \\
$F$ & $90 \%$ & $k$ & 2 \\
\hline
\end{tabular}

Table 1: The values of parameters in model.

Consulting literature [12], this paper set $k$ to 2 which means retailer treats the situation as fairness when it's profit is half of supplier's profit. The effect of $\lambda$ on optimal decisions is shown in table 2. (supplier's utility equals to it's profit) It can be found that:

\begin{tabular}{|c|c|c|c|c|c|c|c|c|}
\hline$\lambda$ & $M^{*}$ & $p^{*}$ & $T^{*}$ & $Q^{*}$ & $\pi_{r}$ & $U_{r}$ & $\pi_{s}$ & $U_{s}+U_{r}$ \\
\hline 0 & 0.091 & 2263 & 0.101 & 891 & 1917889 & 1917889 & 3485610 & 5403499 \\
0.05 & 0.089 & 2252 & 0.098 & 914 & 1869063 & 1864602 & 3648908 & 5513510 \\
0.10 & 0.086 & 2238 & 0.096 & 946 & 1847326 & 1863174 & 3853127 & 5716301 \\
0.15 & 0.084 & 2220 & 0.093 & 979 & 1797780 & 1875822 & 4115842 & 5991664 \\
0.20 & 0.080 & 2197 & 0.089 & 1014 & 1699282 & 1912842 & 4466363 & 6379205 \\
0.25 & 0.076 & 2164 & 0.085 & 1074 & 1490062 & 1984404 & 4957493 & 6941897 \\
0.30 & 0.072 & 2114 & 0.080 & 1161 & 1018946 & 2116059 & 5694935 & 7810994 \\
\hline
\end{tabular}

Table 2: The effect of $\lambda$ on optimal decisions

\begin{tabular}{|c|c|c|c|c|c|c|c|c|}
\hline$k$ & $M^{*}$ & $p^{*}$ & $T^{*}$ & $Q^{*}$ & $\pi_{r}$ & $U_{r}$ & $\pi_{s}$ & $U_{s}+U_{r}$ \\
\hline 1.0 & 0.080 & 2197 & 0.089 & 1162 & 1699282 & 1966232 & 4466363 & 6432595 \\
1.4 & 0.079 & 2187 & 0.088 & 1163 & 1644570 & 1976643 & 4617433 & 6594076 \\
1.8 & 0.077 & 2173 & 0.086 & 1164 & 1555119 & 1983436 & 4823505 & 6806941 \\
2.2 & 0.075 & 2153 & 0.084 & 1165 & 1402478 & 1981563 & 5121296 & 7102859 \\
2.6 & 0.072 & 2122 & 0.080 & 1166 & 1106349 & 1950559 & 5589537 & 7540096 \\
3.0 & 0.068 & 2065 & 0.075 & 1167 & 376029 & 1796297 & 6433130 & 8229427 \\
\hline
\end{tabular}

Table 3: The effect of $k$ on optimal decisions

The effect of $k$ on optimal decisions is shown in table 3. As $k$ increasing, retailer's utility increases firstly and then decreases. With the increase of $k$, retailer's profit is gradually reduced, and supplier's profit is gradually increased. When the profit margin of the supplier increases, the utility of the retailer also increases. when the $k$ is large enough, the supplier's profit margin is not enough to balance the decrease of the retailer's profit. Retailers should take actions at this time to increase it's relative contribution in the channel which means increase it's profit, such as reducing the marginal cost, increasing the demand for products and so on.

\section{Conclusion}

This paper takes fairness concern and delay payment into consideration and establishes a kind of stacklberg game model
(1) The retailer's profit is higher than $\pi_{s} / 2$ when it doesn't have fairness concern. Under this circumstances, Fairness concern will incur retailer's utility less than it's profit. As the extent of fairness concern increasing, retailer's utility presents a decreasing trend. Under this trend, retailer act to reduce price and increase ordering quantity. Because, these decisions increase supplier's profit and shrink the difference between supplier's profit and retailer's profit which will improve retailer's utility. Supplier act to shrink delay payment period under the trend of increasing $\lambda$ which will reduce the loss of interest. Together retailer's and supplier's actions, it is found that supplier's profit shows a increasing trend. Retailer's utility increases as well despite the sacrifice of it's own profit.

(2) While the overall utility of the supply chain is increased, retailer's utility is not always greater than that when $\lambda$ equals to 0 . This shows that when $\lambda$ is relatively small the effect of increasing supplier's profit can sufficient the effect caused by the decrease of retailer's profit on retailer's utility. between supplier and retailer which can solve supplier's optimal delay payment period and retailer's optimal price and ordering quantity. These are found that:

(1) As the extent of fairness concern increasing, retailer act to reduce price and increase ordering quantity, while supplier act to shrink delay payment period.

(2) As relative contribution rate increasing, retailer's utility increases firstly and then decreases. When supplier's profit is very low, retailer could even sacrifice of it's own profit to improve it's utility.

(3) when the extent of fairness concerns are satisfied with certain conditions, retailer's utility and supplier's profit are greater than these under situation of no fairness concerns.

Future research will extend the model of this paper to competition situations under the background of multiple suppliers or retailers. 


\section{References}

[1] S. K. Goyal. Economic Order Quantity under conditions of permissible delay in payments[J]. Journal of the Operational Research Society, 1985, 36(4): 35-38.

[2] J.S. Kim, H. Hwang, S.W. Shinn. An optimal credit policy to increase supplier's profits with price dependent demand functions[J]. Planning and Control, 1995, 6(1): 45-50.

[3] Shien-Ping Huang. Retailer's EOQ model in fuzzy annual demand inventory with limited storage space under partially permissible delay in payments[J]. Journal of Statistics and Management Systems, 2010, 13(3): 651673.

[4] Liang-Yuh Ouyang, Kai-Wayne Chuang. Economic order quantity with allowable shortage and quantity discounts under permissible delay in payments[J]. Journal of Information and Optimization Sciences, 2004, 25(1): 5361.

[5] S.K. Ghosh, K.S. Chaudhuri. An EOQ model with a quadratic demand, time-proportional deterioration and shortages in all cycles[J]. International Journal of Systems Science, 2006, 37(10): 663-672.

[6] S. Khanra, Buddhadev Mandal, Biswajit Sarkar. An inventory model with time dependent demand and shortages under trade credit policy[J]. Economic Modeling, 2013, 35: 349-355.

[7] Yang S, Liang L, Dong J F, An inventory model for single manufacture and multiple retailers under delay in payments[J]. System Engineering, 2007, 25(4): 9-14.

[8] Tony Haitao Cui, Jagmohan S. Raju, Z. John Zhang. Fairness and channel coordination[J]. Management Science, 2007, 53(8): 1302-1314.

[9] Du S F, Du C, Liang L, Liu T Z, Supply chain coordination considering fairness concerns[J]. Journal of Management Sciences in China, 2010, 13(11): 41-48.

[10] Liu S R, Huang Y N, Chen L L. Inventory and pricing decisions in supply chain under fairness concerns[J]. Chinese Journal of Management Science, 2013, 21: 474479.

[11] Zhao D Z, Lv X. Vender managed inventory model considering supplier's fairness preference in supply chain with dominant retailer[J]. Operation Research and Management Science, 2013, 22(3): 45-52

[12] Zhao D Z, Lv X. Vender managed inventory model considering supplier's fairness preference in supply chain with dominant retailer[J]. Operation Research and Management Science, 2013, 22(3): 45-52. 